\title{
Necesidades, libertad y liberación. La cuestión de las necesidades, los deseos y las preferencias en H. Marcuse y F. Hinkelammert: Aproximaciones*
}

\author{
Carlos Javier Asselborn \\ Universidad Católica de Córdoba, Córdoba, Argentina. Email: casselborn@yahoo.com.ar
}

Resumen: El presente texto es un primer acercamiento a la tensión entre las necesidades y preferencias, a partir de dos pensadores significativos para la Teoría Crítica. Herbert Marcuse, miembro de la primera generación de la Escuela de Frankfurt, y Franz Hinkelammert, referente de una renovada Teoría Crítica nacida y continuada creativamente en América Latina. Pensadores que darán elementos esclarecedores para profundizar una problemática que nos preocupa hace tiempo: la cooptación de los deseos y su metamorfosis en necesidades como mecanismo de dominación que opera, no ya en la conciencia sino en la misma sensibilidad humana. ción.

Palabras clave: Marcuse, Hinkelammert, necesidades, deseos, libera-

\section{Needs, freedom and liberation. The issue of needs, desires and preferences in $\mathrm{H}$. Marcuse and $\mathrm{F}$. Hinkelammert: Approaches}

\begin{abstract}
This text is a first approach to the tension existing between needs and preferences derived from the opinion of two significant Critical Theory thinkers: Herbert Marcuse, member of the first generation of the Frankfurt School, and Franz Hinkelammert, referent of the renewed Critical Theory borned and creatively continued in Latin America. Both thinkers will provide enlightening elements to deepen a problem which has been concerning us for some time already: the coopting of the wishes and their metamorphosis into needs as a domination mechanism that operates, not any more in consciousness, but in the very human sensitivity.
\end{abstract}

Key words: Marcuse, Hinkelammert, needs, wishes, liberation.

\section{Necessidades, liberdade e libertação. A questão das necessidades, desejos e preferências em $\mathbf{H}$. Marcuse e $\mathbf{F}$. Hinkelammert: Abordagens}

Resumo: Este trabalho é uma primeira aproximação para a tensão entre as necessidades e preferências dos dois pensadores importantes da Teoria Crítica. 
Herbert Marcuse, um membro da primeira geração da Escola de Frankfurt, Franz Hinkelammert relativa a uma renovada teoria crítica e criativamente continuou nascidos na América Latina. Esclarecedor pensadores que dão itens para mais de uma questão que nos preocupa há muito tempo: a cooptação dos desejos e necessidades metamorfose como um mecanismo de dominação que opera, e não na consciência, mas na sensibilidade muito humana. Libertação.

Palavras-chave: Marcuse - Hinkelammert com Necessidades - Desejos -

$$
* * *
$$

A Osvaldo Ardiles, filósofo de la liberación, del exilio y la intemperie.

“Las necesidades generadas por el sistema son así eminentemente estabilizadoras, necesidades conservadoras: la contrarrevolución en la estructura instintiva”. H. Marcuse, 1969.

"Si hay necesidades, las preferencias o gustos no pueden ser el criterio de orientación hacia los fines” Franz J. Hinkelammert, 2002.

\section{Del presente al pasado: la crítica a la libertad liberal-capitalista}

En estos tiempos convulsionados, la política -entendida ésta como la lucha de los sin parte por formar parte (Rancière, 1996: 25) ${ }^{1}$ - atraviesa la cotidianeidad y sus estados de ánimo. La experiencia histórica señala que la vida social tiene sus emociones, sus sentimientos,... una sensibilidad que la sostiene y que supera las ideas claras y distintas de teorías críticas o ideologías, por cierto, necesarias e ineludibles.

Historicidad y libertad son las experiencias en las que se dilucida el sentido existencial y la lucha por la sobrevivencia del ser humano. No obstante toda libertad, como tal, se historifica, por lo que adquiere entonces un carácter ambiguo, conflictivo, político y, aún - a pesar de muchos/as- dialéctico.

En la actual coyuntura nacional y latinoamericana, la libertad, defendida por ciertos discursos políticamente correctos, suele ser el motivo y el argumento para, en no pocos casos, dejar las cosas como están. Es la libertad como fórmula y cifra para la conservación de un orden, de cierto orden teñido de un resignado conservadurismo.

La máxima amenaza a esta libertad, se vocifera por calles, medios 
de comunicación, estrados, púlpitos y cátedras: el Estado. Esa invención moderna liberal que se ha trastocado y degenerado con la irrupción del Estado de Bienestar, ahora - más que nunca en algunos países latinoamericanos - devenido populista. Para esas voces, el Estado - en tanto garantía de transformaciones en beneficio de las mayorías empobrecidas- es la encarnadura de la demagogia, el autoritarismo y, por supuesto, no podía faltar, la tan conocida y nunca bien ajusticiada "corrupción”2 .

Ahora bien, tampoco podemos pecar de ingenuos y negar estos males, reales por cierto, en la actual conformación de los Estados latinoamericanos, lo que evidencia una crisis profunda de cierta configuración histórica de los mismos. Pero habitualmente se enfatizan los males para proponer luego la disolución de esa “fábrica de corruptos, ladrones e indolentes”. En la actualidad, el sentido común, atravesado por los mediáticos anatemas señala al Estado como aquel Leviatán que cercena las libertades individuales.

Es la Libertad amenazada por las regulaciones pretendidas por el Estado pos-neoliberal demonizado cuando no cumple las funciones por la que surgió en los albores de la modernidad: garantizar la seguridad individual y respetar la propiedad privada. Por lo tanto, ¿Qué libertad es amenazada? y, ¿amenaza para quiénes?.

Cierta vez algún filósofo afirmó que la libertad crecía con la propiedad: a más propiedad, más libertad. El dinero todo lo puede y todo lo transforma. Y esto posibilita la libertad para elegir qué comprar, por dónde circular, qué sentir, de qué reírse y por qué llorar. Su discípulo díscolo y revoltoso afirmará en unos manuscritos que a mayor posesión de dinero, mayor la impotencia...es decir, la muerte de la creatividad, manifestación suprema de la libertad humana ${ }^{3}$.

¿Puede la libertad trastocarse o historizarse -de modo paradójico, impensable en estos tiempos magros- en biología?, ¿Qué base biológica debe suponerse para una libertad más plena? Y también: ¿Qué tipo de libertad se ha naturalizado en nuestros contextos, muchos de ellos embotados por el exceso de estimulación sensible?, ¿A qué valores, representaciones, imaginarios alude ese modo particular de comprender y vivenciar la libertad?, ¿qué monstruos, enemigos, salvajes incorregibles construye esa libertad defendida con uñas y dientes?, ¿o deberemos resignarnos que lo que experimentamos como libertad sea el miedo revestido con y en la propiedad? Y además, ¿podemos hacer experiencia de la libertad sin satisfacer primeramente las necesidades básicas?, ¿̇o la libertad es ya de por sí una necesidad básica?

Muchas y excelentes son las reflexiones que se han hecho a lo largo de la historia sobre este problema. No excluimos esos aportes sino que en algunos casos los subsumimos y presuponemos. La novedad de la temática no reside en su escaso tratamiento en la tradición académica-filosófica/ sociológica sino en la coyuntura histórica en donde se reubica y adquiere inusitados alcances práctico-políticos ${ }^{4}$. 
Pero la libertad, nos dice cierta antropología filosófica, es una conquista y no sólo un elemento más de lo dado. Somos libres en la medida en que nos ponemos en movimiento hacia la libertad. Somos libres en tanto y en cuanto nuestras praxis cotidianas nos posibilitan decir "no" al "orden naturalizado". Ese "no" no se reduce a ciertos discursos que hacen de la "apertura dialógica" la llave que abre la puerta a la solución de conflictos sociales o interpersonales. El "no” es agónico, incluso trágico, combativo, y por eso mismo, es (sin problema en que asumamos rasgos metafísicos) una de las dimensiones constitutivas del ser humano. Ser humano, significa entre otras cosas, capacidad para decir "no" al orden establecido, ese paraíso que a veces impide reconocernos como desnudamente iguales.

Pero el poder "decir no", además de decirlo de muchas maneras, está mediado e historificado. El "no" no se da sin mediaciones históricas, de lo contrario caemos en utopismos ${ }^{5}$ (Hinkelammert, 2002) cuya función es la de generar voluntarismos y, finalmente, desencanto y resignación.

¿Cuáles son las mediaciones históricas más pertinentes y eficaces para lograr el anhelo de libertad e igualdad? Pregunta cuya multiplicidad de respuestas nunca superarán su ambigüedad ensayística, la apuesta histórica y el riesgo de asumir una de tantas.

El presente texto, de eminente carácter exploratorio, es un primer y tímido acercamiento al tema de las necesidades y preferencias a partir de dos pensadores significativos para la Teoría Crítica. H. Marcuse, miembro de la primera generación de la Escuela de Frankfurt y F. Hinkelammert, a nuestro modesto entender, referente de una renovada Teoría Crítica nacida y continuada creativamente en América Latina. Nuestra lectura será limitada, ya que tendrá en cuenta sólo un par de producciones de estos representantes del pensamiento crítico. Repetimos: lo que ponemos a consideración es un ensayo somero y provisorio acerca de una problemática que nos preocupa hace tiempo: la cooptación de los deseos, de la sensibilidad; la presunta metamorfosis de los deseos en necesidades como mecanismo de dominación que opera, no ya en la conciencia sino en la misma sensibilidad humana:

"Cuando el deseo es cooptado su omnipotencia se domestica y la utopía deviene en opio: la (contra) utopía de la propiedad calma el deseo de vivir y lo pervierte en sacrificio y confort. El sistema de opresión es eficaz en su cometido en la medida que coopta la fuente de poder: el deseo” (Asselborn, Cruz, Pacheco, 2009:26).

Deseo, propiedad, placer y miedo serán pues algunas de las categorías que deberán profundizarse para develar la antropología que fundamenta al capitalismo. Germán Gutiérrez señala que fue Adam Smith quien percibió con claridad que el futuro del capitalismo dependía de la constitución de la industria del deseo. (Gutiérrez, 1997: 25). 


\section{Del pasado al presente: La liberación de las necesidades perpetuadoras de la servidumbre}

En el año 1968 Herbert Marcuse, filósofo alemán (1898-1979) escribió una pequeña obra titulada “Ensayo sobre la Liberación” cuya publicación apareció en 1969. 40 años exactamente. Y es esta obra precisamente uno de los textos que lo une con el Mayo Francés. Siendo representante destacado de la Escuela de Frankfurt, uno de sus esfuerzos teóricos fue constituir su crítica a las sociedades industriales capitalistas aunando marxismo con psicoanálisis. El filósofo argentino Osvaldo Ardiles señala tres grandes influencias en el derrotero teórico de Marcuse: a) Heidegger, cuyo obra Ser y Tiempo (1927), "le proveyó una de las categorías fundamentales de su primer período", el concepto de "historicidad" (Geschichtlichkeit); b) la Escuela de Frankfurt con su "Teoría Crítica”; y c) Freud y su "metapsicología”. Además remarca tres etapas en el discurso marcusiano: a) las Obras de juventud (1928-1933) en donde intenta unir la fenomenología heideggeriana con el pensamiento dialéctico marxiano; b) Obras de ruptura y transición (1934-1954) en las que opera un rechazo al heideggerianismo y el contacto con la Escuela de Frankfurt; c) Obras de madurez (1954-1979) cuyo interés está puesto en el análisis de la sociedades avanzadas por medio del cruce entre pensamiento dialéctico-marxiano y psicoanálisis. Un cuarto período queda trunco con su muerte, en el cual ensayó las tareas de la "nueva izquierda” y su vínculo con los movimientos liberacionistas del Tercer Mundo (Ardiles, 1988: 79-106).

Lo que sigue es una ligera aproximación a esta pequeña obra, la cual nos ha dejado asombrados por su contemporaneidad, a pesar de las cuatro décadas transcurridas. En ella, libertad y liberación, crítica, estética y sensibilidad son categorías que se conjugan con lucidez y desprejuiciada apuesta política. Nuestra aproximación adolece de mayores lecturas y profundizaciones, pero pretende mostrar líneas de contacto entre esta obra y algunas búsquedas emprendidas de manera cooperativa hace ya algunos años (Asselborn, Cruz, Pacheco, 2009).

En alguna oportunidad hemos escuchado que la Teoría Crítica esbozada por los representantes de la Escuela de Frankfurt ha sido continuada crítica y creativamente en América Latina por representantes de la filosofía de la liberación (Dussel, 2007) ${ }^{6}$. Osvaldo Ardiles fue el precursor de la recepción de Marcuse dentro de la filosofía de la liberación. En uno de los capítulos de su obra "El Exilio de la razón. Trazos de filosofía y política" (1988) desarrolla una introducción a la vida y obra del filósofo crítico alemán ${ }^{7}$. El escrito de Ardiles presenta además tres textos de Marcuse ("Vicisitudes de la dialéctica", "Nota sobre la dialéctica" y "Hacia el concepto de la negación en la dialéctica”) cuyo hilo conductor es la preocupación por "las condiciones de desarrollo de una dialéctica negativa, destotalizadora, abierta y plural, capaz de superar la inhumanidad vigente" (Ardiles, 1988: 111) ${ }^{8}$. 
Por su parte Horacio Cerutti Guldberg lanza una severa crítica a las lecturas de Marcuse emprendidas por ciertas filosofías de la liberación. El “Ensayo sobre la liberación” fue la obra, -luego de "El hombre unidimensional” (1964)- que mayor impacto tuvo tanto en la teología como en la filosofía de la liberación. Para Cerutti, las lecturas “quirúrgicas” de Marcuse afianzarán la tesis de la “tercera posición”. Los “populistas” destacarán las críticas de Marcuse al marxismo dogmático y con ello, descartarán a Marx de los análisis por europeo, moderno y preso aún de una racionalidad dominadora e imperial (Cerutti Guldberg, 2006: 261-262).

Sin llegar a transformarse en “eco de voz ajena”, la filosofía de la liberación latinoamericana, más allá de las distinciones necesarias y ambigüedades teóricas y prácticas, ha logrado mantener aquella apuesta por la liberación esforzándose por vincular teoría y praxis. Aunque creemos que la clave estética, esbozada por los frankfurterianos no ha sido lo suficientemente subsumida por los latinoamericanos. Clave estética en tanto teoría de la sensibilidad, susceptible de ser cooptada, hoy más que nunca en nuestra América latina que se debate entre la profundización de políticas para la liberación de los pueblos o la restauración conservadora neoliberal. Al respecto volvemos a afirmar nuestra tesis cooperativa: una conciencia crítica es impotente ante una sensibilidad colonizada. O dicho de otra forma: la liberación es inviable ante el deseo y el gusto cooptados. "Por lo tanto la eficacia histórica de la liberación supone la descolonización del deseo, la reapropiación de la corporalidad, que no es posible solo desde la crítica de la conciencia” (Asselborn, Cruz, Pacheco, 2009: 28).

Desde otra clave hermenéutica Alicia Entel junto a Víctor Lenarducci y Diego Gerzovich (2004) nos introducen en la recepción que tuvo en América Latina la Escuela de Frankfurt ${ }^{9}$. Destacan lo aportes de la Escuela en lo referido a la comunicación y la cultura de masas; además de leer críticamente tal recepción que va de Adorno y Horkheimer en los setenta y a W. Benjamin en los ochenta y noventa ${ }^{10}$. La presencia de los planteos de Marcuse es significativa en los setenta, aunque los autores lo contienen en los estudios de comunicación y cultura. Pero no abundaremos más en estos prolegómenos, vayamos a la obra en cuestión.

La obra consta de cuatro capítulos, los dos primeros sumamente lúcidos por la novedad teórica y crítica que inauguran.

Ya en el prólogo Marcuse nos anoticia del poder de sometimiento y sujeción del capitalismo por medio del recurso a la “productividad”. Recurso que, en aquel contexto, obligará a los socialismos a adoptarlo para no quedar atrás en la relación de fuerzas, además de agregar a esta "productividad” la mal habida "burocracia represiva”.

Frente a este poder aplastante, existen iniciativas que se resisten a este embate, pero que aún no superan los estrechos límites de las sociedades establecidas. No obstante, he aquí el optimismo marcusiano tantas veces criticado (para otros crudo pesimismo): existen posibilidades de trasto- 
car ese orden que supone la liberación de las libertades del orden social explotador, "una liberación que deberá preceder a la construcción de una sociedad libre, que exige un rompimiento histórico con el pasado y el presente” (Marcuse, 1969: 8).

Más adelante señalará una objeción a la misma Teoría Crítica que evade la "especulación utópica” por temor a perder la tan mentada "cientificidad". Para el autor, la utopía debe pensarse en tanto y en cuanto su "contenido de irrealidad" ha sido trastocado por la "productividad" capitalista. La tecnología, sea capitalista o socialista, pone en discusión las antiguas coordenadas desde donde se comprendía lo utópico (Ibid: 11).

Se trata pues del problema fundamental de la satisfacción de las necesidades, sus modos e implicancias prácticas, por supuesto, pero mediatamente, teóricas. A saber, ¿qué necesidades debemos satisfacer para alcanzar un modo de vida digno? ¿De qué modo satisfacer esas necesidades? Marcuse se pregunta cómo el individuo puede satisfacer las necesidades "sin dañarse a sí mismo, sin reproducir, mediante sus aspiraciones y satisfacciones, su dependencia respecto de un aparato de explotación que, al satisfacer sus necesidades, perpetúa su servidumbre” (Ibid: 12). Se trata pues de criticar la construcción de necesidades cuya satisfacción esclavizan al ser humano; y a su vez, de señalar otro tipo de necesidad "biológica" que supone el rechazo a tal satisfacción esclavizante. ¿Qué tipo de libertad inauguran estas nuevas formas de vida; es decir, nuevas formas de satisfacer nuevas necesidades, liberadas ya de la agresividad y la dominación? Pero además de lo anterior, tal pregunta señala la cuestión no menor de cómo constituir una praxis política que llegue al nervio mismo de esas formas de sujeción voluntaria:

"Semejante práctica implica un rompimiento con lo familiar, con las formas rutinarias de ver, oír, sentir y comprender las cosas, a fin de que el organismo pueda volverse receptivo a las formas potenciales de un mundo no agresivo y ajeno a la explotación”. (Ibid: 14).

\section{“¿Un fundamento biológico para el socialismo?”}

\section{teórica. \\ Éste es el título que lleva el capítulo primero, de innegable novedad}

La sociedad capitalista es obscena, a pesar de que este término moral siempre es usado por el "establishment". Por lo tanto es necesaria una "terapia lingüística” que permita liberar ciertas palabras de la distorsión y del uso que el sistema hace de ellas. Además de lo anterior, Marcuse señala que debe revisarse el "vocabulario sociológico y político" con el cual se pretende alcanzar la "neutralidad".

La obscenidad presente en la sociedad opulenta es contradictoria, en tanto "la liberalización de la moralidad propia del sistema establecido se realiza dentro del marco de controles efectivos; mantenida dentro de este 
marco, la liberalización fortalece la cohesión de la totalidad” (Marcuse, 1969: 17).

Por lo tanto, una práctica política radical implica rediscutir los valores culturales por los cuales los individuos se conforman en sociedades. Una política que se pretende crítica debe trastocar esa naturaleza instintiva, esa especie de "segunda naturaleza" que producen necesidades de carácter conservador y legitimadoras del orden vigente (Ibid: 19).

Se trata de crear una nueva cultura, una nueva base instintiva y una nueva moral que predisponga al ser humano para la libertad. Para el autor, la moralidad, más allá de constituirse en una comportamiento según criterios sociales o ser expresión de una ideología, es una «disposición» del organismo, enraizada quizás en el impulso exótico que contrarresta la agresividad, para crear y preservar «unidades cada vez mayores» de vida” lo cual permitiría pensar en un "fundamento instintivo para la solidaridad" humana. En una extensa nota al pie de página aclara que el término biológico o biología no se refiere a la disciplina científica sino

“...al proceso y la dimensión en que las inclinaciones, los patrones de comportamiento y las aspiraciones se transforman en necesidades vitales, que, de no ser satisfechas, darían origen a un mal funcionamiento del organismo (...) Si las necesidades biológicas se definen como aquellas que deben ser satisfechas y para las que no puede darse ningún substituto adecuado, ciertas necesidades culturales pueden «sumergirse», adentrándose en la biología del hombre. Podríamos hablar entonces, por ejemplo, de la necesidad biológica de libertad, o de algunas necesidades estéticas que han echado raíces en la estructura orgánica del hombre, en su ' naturaleza», o mas bien, en su 'segunda naturaleza» (Ibid: 18).

Lo anterior, a más de cuarenta años, sigue planteando serios desafíos a las prácticas políticas emancipatorias. Se trata de la construcción de una nueva conciencia, pero también, de una nueva sensibilidad. Esto supone la lucha contra ese tipo de sensibilidad cooptada:

"El capitalismo organizado ha sublimado y deparado un uso socialmente productivo a la frustración y la agresividad primarias, en una escala sin precedente; sin precedente no en términos cuantitativos de violencia, sino más bien en el sentido de su capacidad de producir apaciguamiento y satisfacción de largo alcance; de reproducir la «servidumbre voluntaria» (Ibid: 20).

Una política crítica de liberación debe trastocar esa estructura instintiva, incluso en aquellos sectores sociales con posibilidades de protagonizar el cambio social, de lo contrario, todo intento emancipador está condenado a su fracaso. Este requerimiento fue olvidado incluso por la teoría marxista. La liberación supone “cambios en esta dimensión biológica” y de ella también depende la realización efectiva de la democracia. Libera- 
ción que presupone e inaugura otro tipo de ser humano, con una nueva sensibilidad y una nueva conciencia: "hombres que hablarían un lenguaje diferente, tendrían actitudes diferentes, seguirían diferentes impulsos; hombres que hayan construido una barrera instintiva contra la crueldad, la brutalidad, la fealdad.” (Ibid: 28) y el símbolo de la libertad alcanzada será no sentir más vergüenza de sí mismo (Nietzsche, “La alegre ciencia”, libro III) (Ibid: 29).

\section{Nueva sensibilidad, estética y política}

Esta nueva sensibilidad debe transformarse en factor político cuya función deberá promover una ciencia y una tecnología “para la protección y la gratificación de la vida”. La técnica se convertiría en arte e inauguraría un nuevo ethos estético: “asumiendo las características del arte, traduciría la sensibilidad subjetiva en forma objetiva, en realidad. Ésta sería la sensibilidad de hombres y mujeres que ya no tienen que avergonzarse de sí mismos porque han superado su sentimiento de culpa...” (Ibid: 31).

Es decir, la transformación económica y política supone seres humanos con otro tipo de percepción; supone "hombres fisiológica y psicológicamente capaces de experimentar las cosas, y entre sí, fuera del contexto de violencia y explotación” (Ibid: 32). Esto es, una nueva estética, como forma posible de sociedad libre. Inauguración de una nueva sensibilidad y una nueva imaginación. Con tal planteo, estamos en las puertas de una reinterpretación de la crítica del juicio de Kant que "reconoció la medida en que los sentidos son "productivos», creadores: la medida en que participan en la producción de las imágenes de la libertad” (Ibid: 35). Es la imaginación creativa, pero también imaginación práctica al servicio de la liberación. Y esto supone un nuevo lenguaje, del cual el arte tiene mucho que aportar.

En pleno siglo veintiuno, fuimos adecuados y conformados - sin mucha resistencia por cierto- a un modo de percibir la realidad bajo la forma de la mercancía, la propiedad, el sacrificio, la agresividad cosificante. Lo que viene a recordarnos Marcuse es que toda praxis liberadora debe romper con este "continuum de agresividad y explotación” y la revolución será tal si al mismo tiempo es "una revolución en la percepción que acompañará la reconstrucción material e intelectual de la sociedad, creando el nuevo ambiente estético” (Ibid: 43).

Por eso el arte es la posibilidad de apertura a una "rebelión de la percepción”. A nuestro entender, esto implica romper con ciertos modos de juzgar el alcance del concepto "arte” y las tradicionales distinciones entre arte erudito y arte popular. ¿Cómo prefigurar un arte que trastoque la percepción cooptada, presente ésta también en los sectores sociales explotados, excluidos y empobrecidos? (Pacheco, 2009: 75-93), ¿Qué arte se halla presente en sus vidas amenazadas?

Para Marcuse, el nuevo arte disuelve la vieja estructura de la per- 
cepción, pero no da lugar a un nuevo objeto. La eficacia del nuevo arte está dada en su poder para trastocar lo familiar. Pero hay más todavía, siendo contemporáneo de un proceso de industrialización - que hoy habría que contrastar con los procesos globales de hiper-tecnologización- Marcuse afirma que las sociedades industriales avanzadas y sus consecuencias negativas desafían a la imaginación: "Liberada de la servidumbre a la explotación, la imaginación, apoyada por los logros de la ciencia, podría dirigir su poder productivo hacia una reconstrucción radical de la experiencia y del universo de la experiencia.” (Marcuse, 1969: 51).

Habrá transformación pues, cuando los seres humanos forjen sus vidas y posibiliten un ambiente en donde la lucha por la existencia pierda su fealdad y sus caracteres agresivos... y "lo bello sería una cualidad esencial de su libertad” (Ibid: 51). Para Marcuse se trata del "ethos estético del socialismo” en donde también el arte perdería su privilegio y su dominio sobre la imaginación, la belleza y el sueño. Lo anterior supondría la unión “del arte liberador y de la tecnología liberadora” (Ibid: 53).

\section{Viejos y nuevos sujetos históricos}

En el capítulo tercero Marcuse indica y desarrolla los cambios que el capitalismo está operando en el antiguo sujeto histórico que debía llevar a cabo la liberación: el proletariado. El capitalismo trastoca los lujos en necesidades, restringe la imaginación en mercancía y genera de modo irracional más agresividad. La vida libre y las facilidades tecnológicos conviven con la “intensificación de la lucha por la existencia”. La agresividad se extiende a cualquier blanco, es la agresividad "de aquellos con la experiencia mutilada, con la falsa conciencia y las falsas necesidades, de las víctimas de la represión que, para vivir, dependen de la sociedad represiva y reprimen la alternativa” (Ibid: 55 ).

El autor presenta entonces las dificultades con que se encuentran los sujetos pretendidamente críticos al “sistema”. El capitalismo altera el rol transformador de aquel sujeto histórico porque estabiliza económicamente a la sociedad, a cambio, por supuesto, de mayores exigencias y la aceptación pasiva de consecuencias inhumanas no intencionales. La clase obrera se vuelve así, conservadora y estabilizadora de la sociedad. Los tiempos de Marcuse y su lectura de los mismos le hicieron afirmar lo siguiente: los miembros de la nueva clase obrera (no ya el trabajador manual sino el empleado, el técnico, el ingeniero, el especialista) no tienen ni el interés ni la necesidad de trastocar las relaciones de producción ya que están integrados y bien remunerados. Hoy, en el siglo XXI globalizado, esta afirmación parece contener cierto optimismo ingenuo. Aún parece faltar tal interés, pero también la tan mentada integración y la buena remuneración.

Por lo tanto, para el filósofo frankfurteriano, es en el ámbito de las necesidades en donde habrá que dar batalla si se quiere ser crítico y eficaz: se deberá “desarrollar, en los explotados, la conciencia (y el inconsciente) que aflojaría la presión de esclavizadoras necesidades sobre su existencia 
-las necesidades que perpetúan su dependencia del sistema de explotación.” (Ibid: 61).

Marcuse también hará referencia a otros sujetos contemporáneos a él, a los que marcará sus límites y posibilidades. Entre estos sujetos se encuentra el movimiento estudiantil, susceptible de ser transformado en negocio: la rebelión aplastada por el mercado. También la población negra se constituye en otro sujeto de transformación (recordemos que Marcuse escribe desde los Estados Unidos de América de fines de los 60); pero debe cuidarse que los conflictos de clase se borren por los conflictos raciales. No obstante, estos movimientos, especialmente el estudiantil, "revolucionario en su teoría y en sus instintos" no será ni fuerza revolucionaria ni vanguardia crítica "hasta que no haya masas" capaces de seguirlo.

Con lo anterior aparece el desafío de la academia, especialmente la universitaria, cuya función reside en el desarrollo de una "conciencia auténtica”. El conocimiento pierde así su barniz de neutralidad, se vuelve "trascendente (respecto al mundo de los objetos, respecto a la realidad) no sólo en un sentido epistemológico, sino sobre todo en cuanto va en contra de las fuerzas represivas de la vida: es político” (Ibid: 66).

Luego de explayarse respecto a los sujetos, nuestro autor señala algunos desafíos a tener en cuenta en todo intento de protesta y rechazo a lo establecido. Entre ellos se encuentra la crítica a la democracia formal liberal. La verdadera democracia supone la "abolición de la actual pseudodemocracia” o “anti-democracia capitalista”.

Para Marcuse existe una "dialéctica de la democracia”: por un lado ella es el lugar legítimo en donde deben operarse los cambios, por eso debe ser defendida. Por otro, esta misma democracia es condición de posibilidad para mantener intacto el statu quo, a la vez que reprime todo intento de transformación del mismo. Esta es la ambigüedad con la que se encuentra todo intento de oposición radical al orden establecido. Una lectura desde nuestro presente globalizado y bajo los escombros (reales o virtuales) de aquellos sujetos críticos, obliga a repensar las mediaciones históricas de la misma crítica sin pretender retomar el antiguo debate entre revolución y reformismo. Señalamos los aportes de Marcuse, pero no podemos dejar de indicar ciertos límites producto, por cierto, de los nuevos contextos. Nuestro autor nos anoticia del radicalismo presente en el movimiento juvenil, pero que está ausente en movimientos de base clasista.

Asimismo rescatamos un aporte sugestivo respecto a la creación de alternativas críticas al sistema establecido. Marcuse señala a "la lingüística política” como "coraza del establishment” y afirma la necesidad de crear un lenguaje propio. El lenguaje es una de las formas más eficaces de sujeción y dominio, “define, crea y condena al enemigo". El lenguaje crea al enemigo con las características que necesita el orden establecido para sostenerse en el poder (Ibid: 80-85). Este lenguaje del establishment moviliza la agresividad, 
"En la movilización de esta agresividad se activan, para servir a las necesidades económico-políticas del sistema, antiguas fuerzas físicas: el Enemigo está formado por aquellos que son sucios, que están contaminados; son animales más que humanos; son contagiosos (¡la teoría del dominó!) y amenazan al limpio, anestesiado, saludable mundo libre" (de este modo se referían algunos escritos norteamericanos con respecto a los vietnamitas que combatían) (Ibid:79).

Se trata de re-pensar la legalidad y legitimidad de la "Ley" y el "Orden" a partir de ciertos valores, por cierto, atravesados de ideología y que se constituyen a partir de su propia negación.

Por último nos queda por señalar algunas ideas presentes en el capítulo final titulado "Solidaridad". Se trata pues de la solidaridad que puede existir entre los movimientos liberadores de los países con capitalismo avanzado y los movimientos del Tercer Mundo. La liberación debe surgir primero en el centro del poder. Para que tal acción ocurra hace falta una "solidaridad biológica” que pueda inaugurar nuevas relaciones armónicas entre las necesidades y los objetivos tanto sociales como individuales. Si se pretende instaurar nuevas relaciones sociales, es necesario que las mismas sean anticipadas y demostradas en la lucha, en la praxis histórica. La "nueva Forma de vida" será un proyecto futuro, y por ser proyecto futuro, la antigua forma de vida criticada (la del capitalismo) deberá ser desechada de la lucha:

"La explotación en todas sus formas debe haber desaparecido de esta lucha: tanto de las relaciones de trabajo entre los luchadores, como de sus relaciones individuales. La comprensión, la ternura recíproca, la conciencia instintiva de aquello que es malo, falso, de lo que es herencia de la opresión, confirmarán entonces la autenticidad de la rebelión. Es "la entrada del futuro en el presente". "el sentimiento, la advertencia, de que el gozo de la libertad y la necesidad de ser libres deben preceder a la liberación. (Ibid: 91).

Se trata de un doble proceso, dinámico, dialéctico, conflictivo y sumamente desafiante: la liberación supone la creación de una nueva sensibilidad; pero para que dicha liberación sea realidad, es necesario incorporar a los cuerpos y las conciencias esa misma "nueva sensibilidad". Esta nueva sensibilidad no rechaza las realizaciones de la sociedad industrializadas sino que las incorporará críticamente:

“...desde luego la electrificación, y todos los mecanismos técnicos que alivian y protegen la vida, toda la mecanización que libera la energía y el tiempo humano, toda la estandarización que prescinde de espurios y parasitarios servicios «personalizados» en vez de multiplicarlos multiplicando asimismo los adminículos y demás testimonios de la opulencia explotativa. (Ibid: 93). 


\section{Una sensibilidad liberada "de la esclavitud de las mercaderías" como cifra de una sociedad liberada}

\section{Del futuro utópico al presente: preferencias, deseos y necesidades. Aproximación al concepto de "Reproducción de la vida real” en Franz Hinkelammert}

Franz Hinkelammert es uno de los pensadores situados en América Latina que ha sabido articular con inteligencia esfuerzo crítico y necesidad de emancipación. Articulación que tiene en su crítica de la razón utópica y, recientemente, su crítica de la razón mítica dos referencias ineludibles para develar los fundamentos de la lógica que hace del cálculo de utilidad el único recurso para crear el mejor de los mundos posibles. Razón utópica y razón mítica atraviesan a la actual estrategia capitalista neoliberal y creemos también, en no pocos casos, a ciertas praxis históricas alternativas que pretenden su superación.

La crítica de la razón utópica se ocupa de señalar los límites de la Modernidad, más -creemos- no su disolución. Modernidad entendida como el conjunto de intentos secularizados por llevar a cabo los sueños de la humanidad. Desde el siglo XIX se ha afianzado en el pensamiento social una suerte de "ingenuidad utópica" que surca los proyectos e ideologías políticas de diverso cuño y calibre. Esta denuncia de Hinkelammert se fundamenta en el hecho de que ciertas teorías sociales se esfuerzan en encontrar los modos científico-empíricos para realizar los más altos sueños humanos: la sobrevivencia humana y la reproducción de la vida. Tales esfuerzos producen una suerte de ilusiones trascendentales sustentadas en un progreso infinito que abstrae a la misma condición humana. Se trata de un progreso entendido como aproximación cuantitativa constante hacia la realización de lo "imposible” (utopía). Ésta es la trampa insita en las ciencias empíricas que develará el autor. ${ }^{11}$

Otro tanto ocurre con su reciente crítica de la razón mítica, cuyo objetivo reside en poner en tela de juicio los mitos que - paradójicamenteconstituyen y sostienen a la Modernidad. El proyecto moderno, a pesar de su pretendida lucha contra el mito y la sin razón, opera desde un ensamblaje mítico en el cual el cristianismo y, desde él sus respectivas secularizaciones (liberalismo, socialismo...), es la piedra angular. La modernidad produce nuevos mitos y transforma mitos antiguos: desde Prometeo hasta el Dios hecho hombre, es decir, Dios es ser humano desde siempre (Hinkelammert, 2007: 87-88). La crítica es crítica si opera desde el criterio vida-muerte: "verdad es aquello, con y por la cual se puede vivir" (Ibid: 74). Pero además de esta crítica al mito (del poder, del progreso, de la muerte que promueve la vida), el cometido de Hinkelammert es señalar que existe también un marco mítico que es de liberación, crítico-emancipador ya que expresa la rebelión del sujeto: si dios se hace humano, humanizar el ser humano es la nueva dimensión de toda vida humana (Ibid: 88). No se trata aquí de poner el acento en una cierta fe cristiana que envuelve y condiciona toda 
otra realidad. Se trata sí de reconocer al cristianismo primitivo en tanto diosificación del sujeto y no de la autoridad (como luego ocurrirá con la imperialización del cristianismo).

Tanto en la crítica de la razón utópica como en la crítica de la razón mítica subyace un criterio práctico-teórico, epistemológico agregaríamos que es el de la reproducción de la vida humana. Desde este criterio la crítica se materializa y enriquece ya que supone la articulación de diversas dimensiones del sujeto humano: teórica, práctica y, en última instancia, la dimensión de la misma vida humana: sujeto viviente, base y posibilidad para la racionalidad.

Hinkelammert nos alerta sobre aquellas presuntas racionalidades que no tienen en cuenta este criterio o peor aún, lo invierten provocando así la misma negación de la vida: esto es la irracionalidad de lo racionalizado (Hinkelammert \& Mora Jiménez, 2001). ${ }^{12}$

Es aquí donde se ubica el problema de las necesidades humanas y su satisfacción, problemática, conflictiva y desesperada. Necesidades que constatan material y empíricamente la centralidad del criterio de reproducción de la vida y la centralidad también del sujeto vivo, base del sujeto práctico y del sujeto cognoscente. ("el sujeto cognoscente es una instancia reflexiva del sujeto actuante”) (Hinkelammert, 2002: 318).

La actual estrategia de la globalización capitalista trastoca este criterio y lo invierte convirtiendo ciertas preferencias en necesidades. Éste será el punto nodal que deberá criticarse con lucidez e insistencia, ya que tal estrategia reduce al ser humano a un ser de preferencias: su libertad de elegir es el valor supremo. Y la trampa reside en que esa libertad queda atrapada en la imposibilidad de pensar alternativas que superen la libertad de mercado. La racionalidad medio-fin es la racionalidad que motoriza al mercado, cuyo fin no es la satisfacción de las necesidades, sino la creación y satisfacción de preferencias: allí reside la ganancia. Ya A. Smith afirmaba que la generosidad del panadero y del carnicero no estaba movida por sentimientos de amor, compasión y solidaridad, sino por el interés de ganancia. La sonrisa y amabilidad que inunda los mercados son emociones y sentimientos producto de una profunda espiritualidad atravesada por el gran Capital.

Está claro que nuestro autor inscribe el problema de las necesidades en el marco de la relación entre los sujetos y los fines. En dicho marco aflora la problemática de las ciencias empíricas entendidas como posibilidad limitada de operar sobre la realidad, aunque la realidad siempre trasciende a la experiencia empírica que podemos tener de ella. Aparece de este modo la tensión entre dos dimensiones del sujeto: el sujeto cognoscente que es trascendido por el sujeto actuante. La instancia del sujeto actuante/ práctico revela la existencia de fines, los cuales deben escogerse. La realización de dichos fines posee ciertas condiciones materiales de posibilidad, más allá de la voluntad humana. Las ciencias empíricas están imposibilita- 
das para decir qué fines hay que elegir, sólo pueden señalar que toda realización de fines se inscribe en condiciones que presuponen la "escasez cuantitativa dada”, esto es: los medios siempre son escasos (Ibid: 319). Y aquí es cuando aparece otra instancia del sujeto: el sujeto vivo. No hay sujeto práctico que pueda concebir fines y encaminarse hacia ellos sin tener en cuenta esta dimensión, básica, cercana y con frecuencia olvidada. Todos los fines están orientados hacia el proyecto de vivir:

"Ningún fin determinado se puede deducir del proyecto de vivir, sino que este se realiza a través de los muchos proyectos encaminados hacia fines específicos. Son precisamente estos fines específicos los que conforman y posibilitan las condiciones materiales de la posibilidad del proyecto de vivir”. (Ibid: 319)

Por eso la decisión sobre los fines nunca puede agotarse sobre la relación formal medio-fin, sino que esta misma relación está contenida dentro de un proyecto de vida. Por lo tanto, sólo son factibles aquellos fines que “se integran en algún proyecto de vida”. Si hay fines contrapuestos al mantenimiento de la vida, pues no son factibles. Decidir por lo opuesto es optar por el suicidio. De este modo Hinkelammert niega la posibilidad de una “neutralidad valórica” frente a los fines, ya que la vida depende de qué fines se elijan.

El sujeto vivo, siendo sujeto actuante y sujeto práctico, es un ser natural: transforma la naturaleza y transforma su naturaleza. Como ser natural que es, debe satisfacer ciertas necesidades: “para vivir hay que poder vivir, y para ello hay que aplicar un criterio de satisfacción de las necesidades a la elección de los fines” (Ibid: 321). Por esto nuestro autor afirma que así como el sujeto vivo trasciende al sujeto práctico, también las necesidades trascienden a la elección de los fines.

Se trata pues de una "racionalidad reproductiva” que pone en discusión la totalización de la racionalidad medio-fin, basada en una instrumentalidad de tipo utilitarista. Para Hinkelammert, la racionalidad reproductiva es racionalidad crítica porque reconoce el circuito natural de la vida humana como instancia de toda racionalidad. Ella ofrece el criterio de evaluación de la racionalidad medio fin (Hinkelammert - Mora Jiménez, 2005: 37). Por lo tanto, la concepción de sujeto que subyace a la misma supera la mera formalidad de éste. El sujeto es un sujeto necesitado, corporal, natural. Como ser natural, este sujeto no puede colocarse por encima de las leyes naturales.

Se trata pues de pensar las relaciones sociales a partir de estos dos criterios complementarios: racionalidad reproductiva y sujeto corporal necesitado. La racionalidad estará dada pues si dichos criterios no son negados, olvidados o abstraídos: "Una organización social es racional si permite que todos tengan posibilidad de vivir (naturaleza incluida) y si la muerte de unos no se convierte en condición de vida de otros” (Ibíd.,: 47). 
¿Qué necesidades se deberán satisfacer para seguir viviendo?, ¿Qué se entiende por vida humana?, ¿pueden calcularse los valores que hacen posible el bien común?, ¿ Sobre qué sistemas de necesidades se sustenta la exigencia de su satisfacción? Las respuestas son diversas y algunas de ellas utilizan diversas explicaciones metafísicas-idealistas; otras complejos argumentos cientificistas y biologicistas. Por nuestra parte creemos que ambas explicaciones no se excluyen y que deberían articularse para profundizar los argumentos a favor de la vida humana y la satisfacción de las necesidades básicas que la hacen posible.

No puede dejarse de lado en este análisis el poder condicionante del actual sistema capitalista para crear e imponer preferencias metamorfoseadas en necesidades, cuya satisfacción produce mayor esclavitud, explotación, opresión y exclusión. En este sentido el sugestivo debate mantenido por Antonio Salamanca Serrano y Franz Hinkelammert en torno a la verificación de las necesidades materiales (Salamanca Serrano - Franz Hinkelammert, 2009) puede abrir nuevas pistas para futuras reflexiones. Acordamos entonces con que el capitalismo no se reduce a un sistema económico regido por la lógica mercadocentrista; supone una teoría, hoy neoliberal. Tal teoría "es un metarelato que cumple las funciones de una ideología y que contiene una utopía”. (Vergara, 2001).

\section{Crítica, mediaciones históricas y liberación}

Marcuse es el profeta de la liberación en el centro del poder del Capital. Observa la estela de muertos abandonados por el Capital y las filas de esclavos que no desean liberarse. Eso le preocupa y lo insta a buscar las causas históricas que aprobaron la configuración de una antropología afín a la dominación. Su crítica es sagaz y su propuesta novedosa y descarada: crear una nueva sensibilidad biológica predispuesta para la libertad. Pero la materia prima para dicha creación es la que ya está. Es el barro de lo que somos de donde saldrá este "hombre nuevo" que piensa y siente distinto al pensamiento y sensibilidad del capital. El "hombre nuevo" siente distinto, su nueva sensibilidad lo permea de otra manera. Le hace emocionarse, reír y llorar frente a situaciones distintas por las que lloraba, reía y se emocionaba. La nueva sensibilidad para la libertad y la liberación ya no reirá ante un televisor que muestra cómo los pobres se pelean entre ellos. Ya no llorará ante la imagen un niño hambriento asistido por un personaje o una organización social que no se preguntan por las causas del hambre de ese niño. La nueva sensibilidad tendrá en cuenta en sus análisis que los problemas sociales no pueden reducirse a problemas morales. La nueva sensibilidad, en fin, estará predispuesta a descubrir lo que nos iguala como seres humanos, no lo que nos diferencia, diversifica y otrorifica.

Pero claro, tal vez en la generación de Marcuse y sus jóvenes lectores existía una gran confianza en la voluntad en desmedro de la búsqueda sensata y lúcida de las más eficaces mediaciones analíticas, críticas y políticas. Es la ausencia que notamos en la obra analizada. Ausencia que nos 
preocupa y que es motivada por la historia recibida (las luchas y sus respectivos fracasos, pero también la mayor conciencia de ciertos derechos). Contexto histórico sobrepasado por los “cómo hacer” y no por los “qué hacer”. Problema complejo y no menor, dado el pragmatismo de cierta ingeniería social devenida relación social y un utopismo puritano cuyos fines quedan confundidos con las nubes del topos uranos. La resignación a lo dado o el sueño puritano (mundo sin contradicciones ni conflictos, Estado sin política, vida humana sin dialéctica, etcétera) en situaciones conflictivas salen a la calle tomadas de la mano. De esta manera, los sueños revolucionarios terminan siendo abono para las pasiones restauradoras.

El aporte de Marcuse es haber señalado y criticado las características de la sensibilidad capitalista. Sensibilidad predispuesta a ser dominada y decidida a defender con uñas y dientes su propia servidumbre (Marcuse, 1975: 43). Y, como una especie de reloj despertador, nos alertó sobre la necesidad de una nueva sensibilidad para la libertad. No es poca cosa, visto esto después de 40 años.

Por su parte, creemos que uno de los más importantes aportes de Franz Hinkelammert es la distinción entre conceptos/categorías trascendentales y factibilidad en lo referido a las utopías y proyectos crítico emancipadores. Su crítica a la razón utópica se orienta y articula desde esta contribución teórica. Crítica que por su parte no sopesará sólo la "irracionalidad capitalista” sino también ciertos utopismos socialistas, conservadores y anarquistas.

Creemos que, por expansión, se trata de una crítica a la crítica. Crítica que orienta la necesidad de pensar las mediaciones históricas, institucionales y sujetivas de ciertos proyectos sociales y políticos de transformación social. El criterio de factibilidad supone el límite de todo proyecto humano. Y el límite supremo es la muerte como dato ineludible de toda conditio humana. Se trata de la tensión entre lo utópico y el realismo político. Tensión que se ha expresado a lo largo de la historia, con matices y variadas derivaciones prácticas. Ejemplos no faltan: Platón y la tensión entre el filósofo Rey y la mentira señorial, San Agustín y sus dos ciudades, la esperanza y el miedo en Spinoza y Hobbes, la acción del proletariado en Marx, el príncipe de Maquiavelo o, para el caso latinoamericano la fricción entre identidad cultural y emancipación política en la época independentista. Aún resta por escribirse una historia de las mediaciones entre lo "imposible" y lo "posible" en donde uno de los apartados centrales será la lucha entre los puritanismos morales y los pragmatismos políticos. Para Hinkelammert este límite no puede ser definido por las leyes de las ciencias empíricas: "lo que en la terminología de la ciencia empírica se define como posible 'en principio', es precisamente lo imposible en la realidad” (Hinkelammert, 2002: 385). No obstante, esta crítica de la razón utópica no se propone abolir las utopías ya que las mismas son parte constitutiva de toda conditio humana. Precisamente porque podemos crear e imaginar utopías es que también podemos pensar y crear mediaciones para transformar la realidad. Mediaciones que nunca podrán "actualizar” esas utopías, ya 
que las mismas no son un objetivo o fin a alcanzar sino "criterios de discernimiento” de toda ciencia empírica y praxis socio-política: "no pensar lo imposible es imposible, y sin pensar lo imposible jamás podremos circunscribir el marco de lo posible” (Hinkelammert, 2002: 389).

Por lo pronto diremos que en Hinkelammert es clara su postura frente a la necesidad de regulación de la economía. Dicha tarea será posible desde la recuperación del Estado de derecho a partir de los derechos humanos: "No se puede recuperar la ciudadanía sin recuperar el derecho fundamental a la intervención sistemática en los mercados” (Hinkelammert - Mora Jiménez, 2005: 422). Esta praxis alternativa deberá evitar tres esquemas simplistas que socavan sus pretensiones: a) el mesianismo de corte neoliberal del mercado; b) el posibilismo conservador (utopización de lo real); c) el radicalismo sin mediaciones. (Ibíd., 405-406).

Reiteramos: con Marcuse y Hinkelammert, nuestra crítica se lanza contra el puritanismo moral que socava toda posibilidad de transformación social. La crítica al pragmatismo político no la desarrollamos aquí; medios de comunicación y manuales de política hacen de la misma el capítulo central de sus disquisiciones. Señalamos algunos ejemplos que pueden ilustrar y matizar nuestro punto de vista: para terminar con la pobreza, ¿alcanza con que "los políticos dejen de robar”?; para liquidar la inseguridad ¿alcanza con “dar más educación”?, para convertirnos en “países serios”, ¿alcanza con cristalizar toda política bajo el paradigma del consenso republicano? Es decir, ¿qué grado de ambigüedad, de complejidad y realismo se está dispuesto a aceptar para alcanzar graduales transformaciones en beneficio de las mayorías pauperizadas? Claro que remitirse sólo a un juicio moral o ético nos salvaguarda de la exposición e incluso, de la responsabilidad histórica que recae sobre cada sujeto humano. Responsabilidad que, a riesgo de utilizar metáforas puritanas, siempre se manchará con el barro de la historia en donde la muerte es el máximo límite a todo sueño humano. Pero la muerte, lo sabemos, puede ser el punto de partida para políticas conservadoras (centradas en los discursos ${ }^{13}$ de la seguridad, propiedad, miedo, institucionalidad) o transformadoras (centradas en los discursos de la justicia-igualdad, distribución, poder político, etc.). El argumento de la muerte irrevocable suele ser utilizado para justificar sacrificios y asesinatos cotidianos e imperceptibles. El heideggeriano “ser-para-la-muerte”, ¿no se convierte en la naturalización de la sumisión al "señor de la muerte: a la polis, al Estado, a la naturaleza o al dios”? (Marcuse, 1986:170). ¿Cómo naturalizar pues, el deseo de vivir bien, es decir, desear vivir en una sociedad en donde quepan todos, aunque este deseo implique dejar atrás antiguos estilos de vida e identidades consumistas y propietaristas? 


\section{Notas}

* El presente texto se inscribe en la preparación de nuestra tesis doctoral en Estudios Sociales de América Latina. CEA, UNC: "Crítica al capitalismo y racionalidad reproductiva en Franz Hinkelammert. Aportes al pensamiento crítico latinoamericano”.

1 "La política existe cuando el orden natural de la dominación es interrumpido por la institución de una parte de los que no tienen parte” (Rancière , 1996: 25)

${ }^{2} \mathrm{Al}$ respecto pueden consultarse los aportes de Jorge Vergara: "La concepción de Hayek del estado de derecho y la crítica de Hinkelammert” en Revista Polis $n^{\circ} 10$, Universidad Bolivariana de Santiago. Reproducido en www.revistapolis.cl.

3 "El dinero es el medio y el poder externo, universal (no derivado del hombre como hombre ni de la sociedad humana como sociedad) para transformar la representación en realidad y la realidad en una mera representación. Transforma las facultades humanas reales y naturales en simples representaciones abstractas, es decir, en imperfecciones y quimeras torturadoras; y, por otra parte, transforma las imperfecciones reales y las fantasías, facultades que son en realidad impotentes y que sólo existen en la imaginación del individuo, en facultades y poderes reales. A este respecto, el dinero es la inversión general de las individualidades...” (Marx, 1987: 174).

${ }^{4}$ Nos referimos a los aportes de Hegel, los anarquistas, Marx, Heidegger, Fromm, Sartre, Lévinas, y otros/as además de la tradición liberacionista latinoamericana.

${ }^{5}$ Hinkelammert plantea que la idealización o imaginación de una realidad perfecta peca de ingenua a la hora de pretender concretar en términos absolutos esa perfección. Y se vuelve peligrosa cuando se olvida del límite de la misma realidad y de la inexcusable finitud y límite también de la condición humana. Cf. Asselborn C. - Pacheco O. "La epistemología y sus ambigüedades en los procesos de liberación”. Ponencia presentada en las IV Jornadas Intercátedras de Pensamiento Latinoamericano. UNC - Córdoba 2009. Inédito.

${ }^{6}$ Remitimos especialmente al texto "Desde la Teoría Crítica a la Filosofía de la Liberación (Algunos temas para el diálogo)”, pp. 335-355. "La 'materialidad' de la primera Escuela de Frankfurt consiste en la afirmación de la corporalidad (leiblichkeit) viviente (A. Schopenhauer, F. Nietzsche) vulnerable, que tiene deseos (S. Freud), que necesita comer, vestirse, tener una casa (L. Feuerbach). Esa materialidad antropológica, lejana al materialismo dialéctico soviético, nos era muy sensiblemente cercana en una América Latina sufriente, empobrecida, hambrienta”, p. 337.

${ }^{7}$ El capítulo en cuestión lleva por título “Itinerario de Herbert Marcuse” el cual había aparecido en 1981 en la Revista de la Universidad de Guadalajara, n 11, pp. 5-26.

${ }^{8}$ Ardiles señala que esta preocupación compartida con Marcuse sucede en su estadía en Alemania en donde desarrollaba estudios de post-grado en la Johann Wolfang Goethe Universität de Frankfurt am Main entre los años 1969-1970, bajo la dirección de Jürgen Habermas.

${ }^{9}$ Especialmente el capítulo VI: La Escuela de Frankfurt en América Latina, pp 201-234.

${ }^{10}$ Llama la atención la visita permanente de cierta intelectualidad a los planteos de Benja- 
Polis, Revista de la Universidad Bolivariana, Volumen 10, $N^{\circ}$ 28, 2011

mín durante estas décadas posdictatoriales y posmodernas. Para profundizar esta recepción crítica de dichas lecturas cf. Forster, 2009.

${ }^{11}$ Para ampliar estas referencias Cf. Asselborn C. - Pacheco O. "La epistemología y sus ambigüedades en los procesos de liberación”. Ponencia presentada en las IV Jornadas Intercátedras de Pensamiento Latinoamericano. UNC - Córdoba 2009. Inédito.

${ }^{12}$ De los mismos autores y en continuidad con esta obra: Hacia una economía para la vida. DEI, San José de Costa Rica, 2005.

${ }^{13}$ Nótese que decimos discursos entendiendo que los mismos estás atravesados de simplificaciones conceptuales, ambigüedades teóricas, límites prácticos confusos, con ineludibles cargas ideológicas y retóricas. Discursos que se emiten desde lugares de enunciación que impactan en profundidad en la sensibilidad social. 


\section{Bibliografía}

Ardiles, Osvaldo. (1988), El Exilio de la razón. Trazos de filosofía y política, Ediciones Sils María, Córdoba.

Asselborn, Carlos; Cruz, Gustavo; Pacheco, Óscar (2009), Liberación, estética y política. Aproximaciones filosóficas desde el Sur, EDUCC, Córdoba.

Cerutti Guldberg, Horacio (2006 - 3a edición),. Filosofía de la liberación latinoamericana, FCE, México DF.

Dussel, Enrique, (2007), Materiales para una política de la liberación, Plaza y Valdez SL., México DF.

Elizalde Hevia, Antonio; Martí Vilar, Manuel y Martínez Salvá, Francisco (...), "Una revisión crítica del debate sobre las necesidades humanas desde el Enfoque Centrado en la Persona”, en Revista Polis $n^{\circ} 15$, Universidad Bolivariana de Santiago. Reproducido en www.revistapolis.cl.

Entel, Alicia, Lenarduzzi, Víctor y Gerzovih, Diego (2004), Escuela de Frankfurt. Razón, arte y libertad, Eudeba, Buenos Aires.

Fernández Nadal, Estela y Vergara, Jorge (Editores) (2006), Racionalidad, utopía y modernidad. El pensamiento crítico de Franz Hinkelammert. Homenaje en sus 75 años. Chile, Editorial Universidad Bolivariana S.A.

Gutiérrez, Germán (1997), “Ética funcional y ética de la vida”, en Revista Pasos $n^{\circ}$ 74, pp 19-33 Costa Rica, DEI, Noviembre - Diciembre.

Forster, Ricardo (2009), Benjamín. Una introducción, Quadrata, Buenos Aires.

Heller, Agnes (1986), Teoría de las necesidades en Marx. Ediciones Península. Segunda edición, Barcelona.

Ídem (1996), Una revisión de la teoría de las necesidades. Paidós, Barcelona.

Hinkelammert, Franz Joseph (2002), Crítica de la razón utópica, Desclée de Brouwer, Bilbao.

Ídem (2005), Solidaridad o suicidio colectivo. Editorial Universidad de Granada, Granada.

Ídem (2007), Hacia una crítica de la razón mítica. El laberinto de la modernidad. Materiales para la discusión, Arlekín, San José de Costa Rica.

Ídem (2009), Respuesta de Franz Hinkelammert a Antonio Salamanca. En 
http://redsimonrodriguez.blogspot.com/2009/03/respuesta-de-franzhinkelammert-antonio.html (consulta 7 de Enero de 2010).

Ídem (2006), "Prometeo, el discernimiento de los dioses y la ética del sujeto. Reflexiones sobre un mito fundante de la modernidad”, en Revista Polis $N^{o}$ 13. Universidad Bolivariana de Santiago. También en: www.revistapolis.cl

Ídem (2007), “Humanismo y violencia”, en Revista Polis $N^{o} 16$. Universidad Bolivariana de Santiago. También en: www.revistapolis.cl

Ídem (...), “Sobre la reconstitución del pensamiento crítico”, en Revista Polis $N^{\circ}$ 21. Universidad Bolivariana de Santiago. También en: www.revistapolis.cl

Hinkelammert, Franz \& Mora Jiménez, Henry (2001), Coordinación social del trabajo, Mercado y reproducción de la vida humana. Preludio a una teoría crítica de la racionalidad reproductiva, DEI, San José de Costa Rica.

Ídem (2005), Hacia una economía para la vida. DEI, San José de Costa Rica.

Jay, Martin (1974), La imaginación dialéctica. Historia de la Escuela de Frankfurt y el Instituto de Investigación Social (1923-1950). Taurus, Madrid.

Marcuse, Herbert. (1969), Ensayo sobre la liberación, Joaquín Mortiz S.A. México DF.

Ídem (1975), Sociedad carnívora. Eco Contemporáneo: Buenos Aires.

Ídem (1986), Ensayos sobre política y cultura, Planeta-Agostini, Barcelona.

Marx, Karl (1987), Manuscritos económico-filosóficos, FCE, $11^{\text {a }}$ reimpresión, México.

Pacheco, Óscar (2009), “Estética y política en Latinoamérica”, en Asselborn, Cruz, Pacheco, Liberación, estética y política. Aproximaciones filosóficas desde el Sur (pp. 75-93), EDUCC, Córdoba.

Rancière, Jacques (1996), El desacuerdo. Política y filosofía, Ediciones Nueva Visión, Buenos Aires.

Salamanca Serrano, Antonio (2009), La verificación de la satisfacción de las necesidades materiales criterio para juzgar el utilitarismo, el consecuencialismo y la ética del bien común. En http:// redsimonrodriguez.blogspot.com/2009/02/la-verificacion-de-la- 
satisfaccion-de.html (consulta 7 de Enero de 2010)

Ídem (2009), Respuesta a las observaciones de F. Hinkelammert. En http:/ /redsimonrodriguez.blogspot.com/2009/04/la-revolucion-radical-es-larevolucion.html (consulta 7 de Enero de 2010).

Vergara, Jorge (2001), "La contribución de Hinkelammert a la crítica latinoamericana la neoliberalismo”, en revista Polis $N^{o}$ 2, Universidad Bolivariana de Santiago. Reproducido en www.revistapolis.cl.

Ídem (2002), “El nihilismo al desnudo. Los tiempos de la globalización de Hinkelammert” en Revista Polis $N^{\circ} 4$. Universidad Bolivariana de Santiago. También en: "www.revistapolis.cl”

Recibido: 24.03.2010

Aceptado: 22.09.2010 